\title{
Manual ventilation quality is improved with a real-time visual feedback system during simulated resuscitation
}

\author{
Jeffrey R. Gould ${ }^{1}$, Lisa Campana', Danielle Rabickow², Richard Raymond ${ }^{2}$ and Robert Partridge ${ }^{3 *}$
}

\begin{abstract}
Introduction: Manual ventilations during cardiac arrest are frequently performed outside of recommended guidelines. Real-time feedback has been shown to improve chest compression quality, but the use of feedback to guide ventilation volume and rate has not been studied. The purpose of this study was to determine whether the use of a real-time visual feedback system for ventilation volume and rate improves manual ventilation quality during simulated cardiac arrest.

Methods: Teams of 2 emergency medical technicians (EMTs) performed two 8-min rounds of cardiopulmonary resuscitation (CPR) on a manikin during a simulated cardiac arrest scenario with one EMT performing ventilations while the other performed compressions. The EMTs switched roles every 2 min. During the first round of CPR, ventilation and chest compression feedback was disabled on a monitor/defibrillator. Following a 20-min rest period and a brief session to familiarize the EMTs with the feedback technology, the trial was repeated with feedback enabled. The primary outcome variables for the study were ventilations and chest compressions within target. Ventilation rate (target, 8-10 breaths/minute) and tidal volume (target, $425-575 \mathrm{ml}$ ) were measured using a novel differential pressure-based flow sensor. Data were analyzed using paired $t$ tests.
\end{abstract}

Results: Ten teams of 2 EMTs completed the study. Mean percentages of ventilations performed in target for rate $(41 \%$ vs. $71 \%, p<0.01)$, for volume (31\% vs. $79 \%, p<0.01)$, and for rate and volume together (10\% vs. $63 \%, p<$ 0.01 ) were significantly greater with feedback.

Conclusion: The use of a novel visual feedback system for ventilation quality increased the percentage of ventilations in target for rate and volume during simulated CPR. Real-time feedback to perform ventilations within recommended guidelines during cardiac arrest should be further investigated in human resuscitation.

Keywords: Airway, Cardiopulmonary resuscitation (CPR), Tidal volume, Ventilation

\section{Introduction}

High-quality ventilations are a critical component of cardiac arrest resuscitation; however, it is known that ventilations are commonly performed outside of recommended guidelines [1, 2]. Hyperventilation is associated with

\footnotetext{
* Correspondence: robert_partridge_md@brown.edu

${ }^{3}$ Department of Emergency Medicine, Emerson Hospital, 133 ORNAC, Concord, MA 01742, USA

Full list of author information is available at the end of the article
}

adverse hemodynamic effects [3, 4]; higher tidal volumes and end-expiratory pressures increase pulmonary vascular resistance and reduce cardiac output [5]. Currently, there are no reliable tools available that provide real-time ventilation feedback to guide rescuers during resuscitation.

Properly delivered manual ventilations are challenging to achieve during resuscitation. During cardiac arrest, oxygen delivery to critical organs is limited by blood flow rather than arterial oxygen content $[6,7]$. A 
ventilation bag may be used to perform rescue breaths before and after placement of an advanced airway, unless a mechanical ventilator is used. During any type of manual ventilation, adequate tidal volumes can be difficult to achieve, and complications are well described [8]. It is known that healthcare professionals commonly perform ventilations outside of recommended guidelines during CPR $[3,9]$ and that higher respiratory rates and elevated tidal volumes are associated with poor outcomes.

A new technology (AccuVent ${ }^{\text {twx }}$, ZOLL Medical, Chelmsford, MA) has been developed to provide real-time feedback on ventilation quality to healthcare professionals during resuscitation. This technology comprises a differential pressure-based flow sensor that is placed between the ventilation bag and airway to measure respiratory rate and ventilation volume during resuscitation. This information is then displayed numerically and graphically on a defibrillator/monitor in real time to guide rescuers in delivering manual ventilations within recommended guidelines (Fig. 1, Fig. 2).

Real-time feedback has previously been shown to improve chest compression quality and patient survival during human resuscitation [10-12]. However, the effects of real-time feedback to guide delivery of ventilations at the appropriate rate and tidal volume have not been examined. The purpose of this study was to determine whether the use of a real-time visual feedback system improves the quality of manual ventilations during simulated cardiac arrest.

\section{Methods}

Basic life support (BLS) and advanced life support (ALS) emergency medical technicians (EMTs) volunteered for the study and worked in pairs. Potential participants were excluded if they were CPR instructors, had known health problems that could limit physical performance, or were pregnant. In an effort to minimize the Hawthorne effect, the true purpose of the study was not disclosed to participants. Instead, they were told that the study was investigating levels of fatigue experienced while performing CPR.

This investigation was approved by the New England Institutional Review Board (IRB \#: 120170151). Written informed consent was obtained from all participants. For each pair of participants, the study involved a 1-hour session, which included being familiarized with the study protocol, completing a demographic questionnaire, and performing two simulated cardiac arrest trials.

\section{Simulated cardiac arrest trials}

Participants worked in pairs to perform two trials of a simulated cardiac resuscitation on an intubated manikin (Simulaids, Saugerties, NY). A monitor/defibrillator (X Series $^{\circ}$, ZOLL Medical, Chelmsford, MA) was placed next to the manikin and training defibrillator pads with an accelerometer-based sensor were placed on the chest. During each trial, EMTs performed CPR for a total of 8 min. One EMT performed compressions while the other performed manual ventilations using a ventilation bag. EMTs switched roles every 2 min. Each EMT performed 2 rounds of compressions and 2 rounds of ventilations during each trial.

During the first trial, ventilation and chest compression feedback features were disabled on the defibrillator/ monitor. Following a 20-min rest period and a brief session to familiarize participants with the feedback

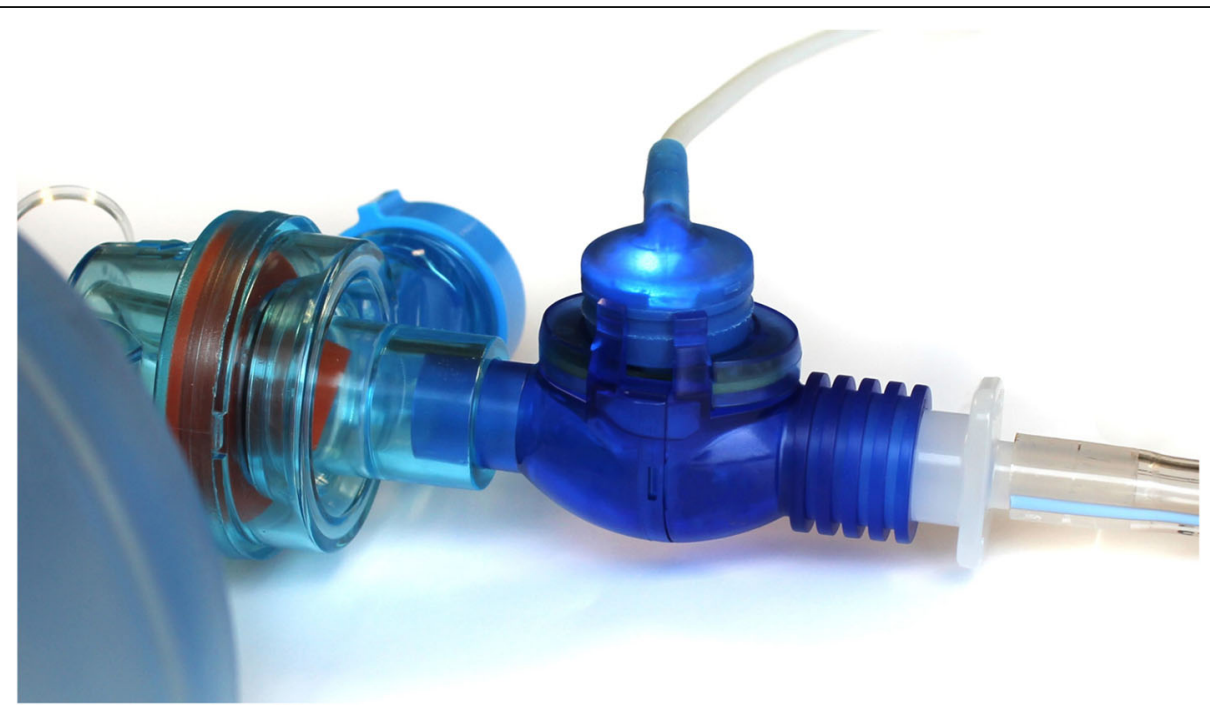

Fig. 1 Disposable differential pressure-based flow sensor used to measure ventilation rate and tidal volume. Shown attached to a ventilation bag, endotracheal tube, and a reusable cable (ZOLL Medical, AccuVent) 


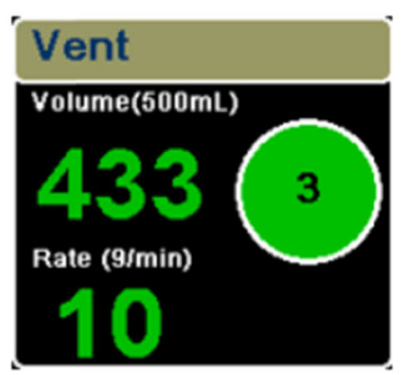

\section{Real Vent Help Feedback following an in-target ventilation displayed in green. \\ Count down timer for rescuer to prepare for another ventilation.}

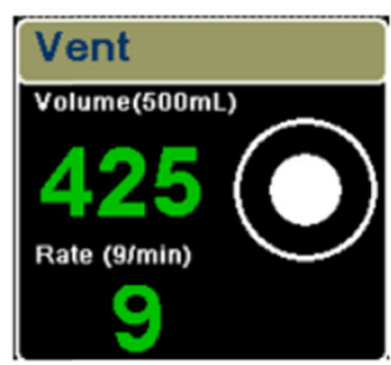

\section{Upon initiating a ventilation, the circle begins to fill from center. Complete filling of the circle signals the rescuer to stop the ventilation.}
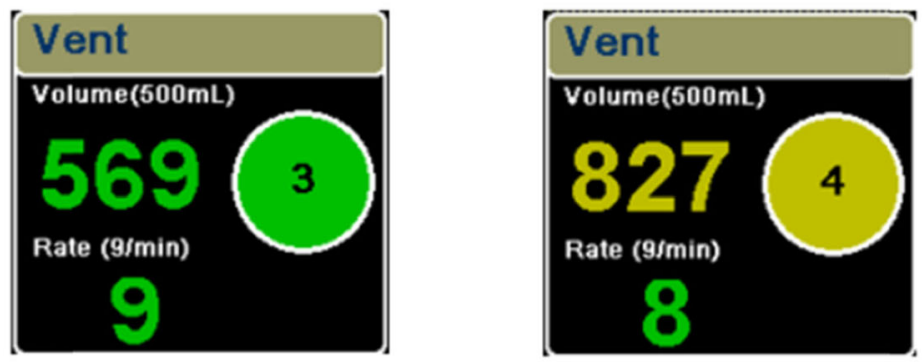

\section{In-target ventilations are displayed in green, while out-of-target ventilations are displayed in yellow.}

Fig. 2 Real Vent Help dashboard display of real-time feedback on ZOLL X series defibrillator/monitor

dashboards displayed on the monitor, the trial was repeated with real-time feedback on ventilation and compression quality enabled on the monitor.

\section{Outcome variables}

The primary outcome variables for the study were ventilations and chest compressions within target, measured before and after the intervention of real-time feedback. Ventilation rate (target, $8-10$ breaths/minute) and tidal volume (target, $500 \pm 75 \mathrm{ml}$ ) were measured using the AccuVent $^{\text {tw }}$ sensor. Real-time feedback showing rate and volume of each ventilation was displayed numerically and graphically on the monitor (Fig. 2). Chest compression depth (target, 2-2.5 in.) and rate (target, 100-120 compressions/minute) were measured using an accelerometer-based system embedded within the electrodes placed on the manikin's chest (Real CPR Help, ZOLL).
Paired $t$ tests were used to compare trials performed without feedback to those from the second trial with feedback enabled.

\section{Results}

Twenty EMTs (4 females) with a range of clinical experience participated in the study. The median age of participants was 28 years (IQR $=23-40$ years). All participants held current CPR certification, 13 held basic life support (BLS) certification, and 7 held advanced cardiac life support (ACLS) certification. The median time spent employed in emergency medical services (EMS) was 3 years (IQR $=2-17$ years) (Table 1$)$.

Mean percentages of ventilations performed in target for rate $(41 \%$ vs. $71 \%, p<0.01)$, for volume $(31 \%$ vs. $79 \%, p<0.01)$, and for rate and volume together $(10 \%$ vs. $63 \%, p<0.01$ ) were significantly greater with feedback. Similarly, the percentage of chest compressions that were performed in target for rate $(36 \%$ vs. $76 \%, p<$ 
Table 1 Participant characteristics

\begin{tabular}{|c|c|}
\hline$n$ & 20 (4 females) \\
\hline Age (years) & $28($ IQR 23,40) \\
\hline Years employed in EMS & $3(\mathrm{IQR} 2,17)$ \\
\hline \multicolumn{2}{|l|}{ Training $(n)$} \\
\hline BLS certified & 13 \\
\hline ACLS certified & 7 \\
\hline \multicolumn{2}{|l|}{ Last certification $(n)$} \\
\hline$<3$ months & 9 \\
\hline $3-6$ months & 1 \\
\hline 6-12 months & 6 \\
\hline$>12$ months & 4 \\
\hline \multicolumn{2}{|c|}{$\begin{array}{l}\text { Number of times performing compressions during human cardiac arrest } \\
(n)\end{array}$} \\
\hline Never & 4 \\
\hline $1-5$ & 3 \\
\hline $6-10$ & 5 \\
\hline $11-15$ & 0 \\
\hline $16-20$ & 0 \\
\hline$>20$ & 8 \\
\hline \multicolumn{2}{|c|}{$\begin{array}{l}\text { Number of times performing ventilations during human cardiac arrest } \\
(n)\end{array}$} \\
\hline Never & 2 \\
\hline $1-5$ & 4 \\
\hline $6-10$ & 1 \\
\hline $11-15$ & 3 \\
\hline $16-20$ & 1 \\
\hline$>20$ & 9 \\
\hline
\end{tabular}

Age and years employed in EMS presented as median (IQR)

$0.01)$, for depth (34\% vs. $70 \%, p<0.01)$, and for rate and depth together ( $16 \%$ vs. $55 \%, p<0.01)$ was significantly greater with the use of visual feedback (Table 2).

\section{Discussion}

This investigation demonstrated that real-time ventilation feedback, used in simulated cardiac arrest resuscitation, improves ventilation quality. In addition, simultaneous display of real-time compression feedback improved chest compression quality, demonstrating that the improvement in ventilation quality did not come at the expense of compression quality. Prior studies have shown that real-time feedback improves compression quality [10], and improved compression quality has been shown to improve patient survival $[11,12]$. Real-time feedback for ventilation rate and volume has not previously been reported.

Ventilations performed by health care professionals during resuscitations are frequently performed outside of recommended guidelines for both rate and tidal volume $[2,3,9]$. Excessive ventilation rate and/or tidal volume have been shown to be detrimental to survival [1]. Providing real-time feedback on ventilation rate and tidal volume to rescuers may improve rescuer performance according to established resuscitation guidelines and as a result may reduce the risk of detrimental outcome due to excessive ventilation rates and tidal volumes. Avoiding hyperventilation and excessive tidal volumes may result in improved patient survival.

\section{Limitations}

The main limitation of the study is that the order of the CPR trials was not randomized, although this design has been successfully used in other feedback studies. All participants performed CPR without feedback in the first trial. While it is possible that a learning effect may have led to an increase in compression and ventilation quality in the second trial, a secondary analysis showed that the number of compressions and ventilations in target during the first 2-min round did not differ from the second 2-min round. A lack of improvement within trials suggests that any potential learning effect was minimal.

Interpretation of the findings in this study can only be applied to the simulation setting. Although the use of ventilation feedback in patient resuscitation is feasible, other factors associated with actual resuscitation may adversely affect the performance of the ventilation monitoring technology. Human studies using real-time ventilation feedback during resuscitation will be useful to determine the effectiveness of ventilation feedback technology in the clinical setting and determine whether

Table 2 Ventilations and compressions performed in target with and without the use of real-time feedback

\begin{tabular}{llll}
\hline & No feedback & Feedback & $P$ \\
\hline Compressions in target for rate (\%) & $36 \pm 36$ & $76 \pm 26$ & $70 \pm 25$ \\
Compressions in target for depth (\%) & $34 \pm 30$ & $55 \pm 28$ & $<0.01$ \\
Compressions in target for rate and depth (\%) & $16 \pm 25$ & $71 \pm 16$ & $<0.01$ \\
Ventilations in target for rate (\%) & $41 \pm 23$ & $79 \pm 15<0.01$ \\
Ventilations in target for volume (\%) & $31 \pm 32$ & $63 \pm 18<0.01$ \\
Ventilations in target for rate and volume (\%) & $10 \pm 14$ & $<0.01$ \\
\hline
\end{tabular}

Data presented as mean \pm standard deviation 
real-time feedback on ventilation quality improves outcome after cardiac arrest.

\section{Conclusion}

The use of a ventilation feedback system in simulated cardiopulmonary resuscitation improved ventilation quality by increasing the number of manual ventilations performed within target for rate and volume. This technology may address an unmet need in resuscitation medicine. Real-time ventilation feedback during resuscitation should be further studied in humans to determine the effectiveness of feedback technology on ventilation quality and outcome after cardiac arrest.

\section{Abbreviations \\ EMTs: Emergency medical technicians; CPR: Cardiopulmonary resuscitation; BLS: Basic life support; ALS: Advanced life support; IRB: Institutional Review Board; ACLS: Advanced cardiac life support; EMS: Emergency medical services}

\section{Acknowledgements}

Not applicable

\section{Authors' contributions}

RP and JRG conceived and designed the study. All listed authors have made substantial contributions to acquisition of data or analysis/interpretation of data. All listed authors have drafted or reviewed the article for important intellectual content and accuracy and have approved the final submitted version.

\section{Funding}

ZOLL Medical Corporation funded the study. Employees of Zoll Medical Corporation contributed to all aspects of the study (study design, data collection, data analysis and interpretation, writing of the manuscript, and decision to publish)

\section{Availability of data and materials}

The datasets used and/or analyzed during the current study are available from the corresponding author on reasonable request and with permission of Zoll Medical Corporation.

\section{Ethics approval and consent to participate}

This investigation was approved by the New England Institutional Review Board (IRB \#: 120170151), and written informed consent was obtained from all participants.

\section{Consent for publication}

Not applicable

\section{Competing interests}

Author RP is a consultant for ZOLL Medical Corporation. Author JRG and LC are employed by ZOLL Medical Corporation.

\section{Author details}

${ }^{1}$ ZOLL Medical, Chelmsford, MA, USA. ${ }^{2}$ Armstrong Ambulance, Arlington, MA, USA. ${ }^{3}$ Department of Emergency Medicine, Emerson Hospital, 133 ORNAC, Concord, MA 01742, USA.

Received: 23 July 2019 Accepted: 1 April 2020

Published online: 16 April 2020

\section{References}

1. O'Neill JF, Deakin CD. Do we hyperventilate cardiac arrest patients? Resuscitation. 2007;73:82-5.

2. Web-based integrated 2010 and 2015 American Heart Association Guidelines for Cardiopulmonary Resuscitation and Emergency Cardiovascular Care. Available at: https://eccguidelines.heart.org/index.php/ circulation/cpr-ecc-guidelines-2/part-7-adult-advanced-cardiovascular-lifesupport/. Accessed 7 Apr 2020

3. Aufderheide TP, Sigurdsson G, Pirrallo RG, Yannopoulis D, McKnite S, von Briesen C, et. al. Hyperventilation-induced hypotension during cardiopulmonary resuscitation. Circulation. 2004; 109:1960-1965.

4. Karlsson T, Stjernstrom EL, Stjernstrom H, Norlen K, Wiklund L. Central and regional blood flow during hyperventilation. An experimental study on the pig. Acta Anaesthesiol Scand. 1994;38:180-6.

5. Cheifetz IM, Craig DM, Quick G, McGovern JJ, Cannon ML, Ungerleider RM, et al. Increasing tidal volumes and pulmonary overdistension adversely adversely affect pulmonary vascular mechanics and cardiac output in a pediatric swine model. Crit Care Med. 1998;26:710-6.

6. Chandra NC, Gruben KG, Tsitlik JE, Brower R, Guerci AD, Halperin HH, et al. Observations of ventilation during resuscitation in a canine model. Circulation. 1994:90(6):3070-5.

7. Ornato JP, Garnett AR, Glauser FL. Relationship between cardiac output and the end-tidal carbon dioxide tension. Ann Emerg Med. 1990;19:1104-6.

8. Ocker $H$, Wenzel V, Schmucker P, Dorges V. Effectiveness of various techniques in a bench model simulating a cardiac arrest patient. J Emerg Med. 2001;20:7-12.

9. Milander MM, Hiscok PS, Snaders AB, Kern KB, Berg RA, Ewy GA. Chest compression and ventilation rates during cardiopulmonary resuscitation: the effects of audible tone guidance. Acad Emerg Med. 1995;2:708-13.

10. Crowe C, Bobrow BJ, Vadeboncoeur TF, Dameff C, Stolz U, Silver A, et al. Measuring and improving cardiopulmonary resuscitation quality inside the emergency department. Resuscitation. 2015:93:8-13.

11. Bobrow BJ, Vadeboncoeur TF, Stolz U, Silver AE, Tobin JM, Crawford SA, et al. The influence of scenario-based training and real-time audiovisual feedback on out-of-hospital cardiopulmonary resuscitation quality and survival from out-ofhospital cardiac arrest. Ann Emerg Med. 2013;62(1):47-56.

12. Davis DP, Graham PG, Husa RD, Lawrence B, Minokadeh A, Altieri K, et al. A performance improvement-based resuscitation programme reduces arrest incidence and increases survival from in-hospital cardiac arrest. Resuscitation. 2015;92:63-9.

\section{Publisher's Note}

Springer Nature remains neutral with regard to jurisdictional claims in published maps and institutional affiliations.
Ready to submit your research? Choose BMC and benefit from:
- fast, convenient online submission
- thorough peer review by experienced researchers in your field
- rapid publication on acceptance
- support for research data, including large and complex data types
- gold Open Access which fosters wider collaboration and increased citations
- maximum visibility for your research: over $100 \mathrm{M}$ website views per year
At BMC, research is always in progress.
Learn more biomedcentral.com/submissions 